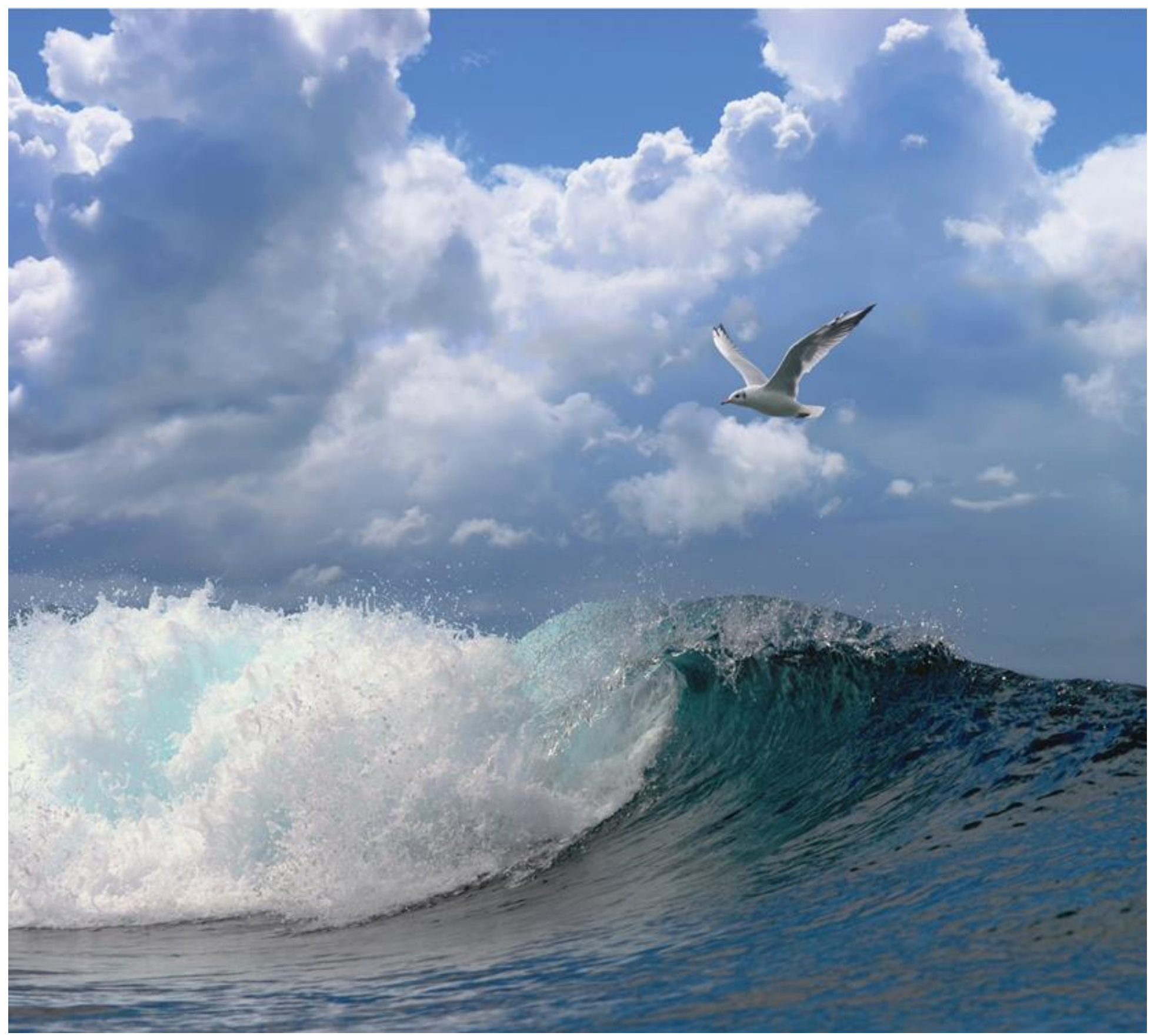

Practical implementation of real-time fish classification from acoustic broadband echo sounder data - RealFishEcho 


\section{Practical implementation of real-time fish classification from acoustic broadband echo sounder data - RealFishEcho}

Classification algorithm improvements

Authors: $\quad$ B.J.P. Berges, A.T.M.. van Helmond

Publication date: 1th February 2018 
B.J.P. Berges, A.T.M.. van Helmond, 2018. Practical implementation of real-time fish classification from acoustic broadband echo sounder data - RealFishEcho; Classification algorithm improvements. Wageningen, Wageningen Marine Research (University \& Research centre), Wageningen Marine Research report C010/18. $15 \mathrm{pp}$.

Client: $\quad$ Mr. Martin Pastoors mpastoors@pelagicfish.eu

PFA

Louis Braillelaan 80

2719 EK Zoetermeer

The Netherlands

This report can be downloaded for free from https:// doi.org/10.18174/440683

Wageningen Marine Research provides no printed copies of reports.

(C) 2016 Wageningen Marine Research Wageningen UR

Wageningen Marine Research institute of Stichting Wageningen Research is registered in the Dutch traderecord nr. 09098104, BTW nr. NL 806511618
The Management of Wageningen Marine Research is not responsible for resulting damage, as well as for damage resulting from the application of results or research obtained by Wageningen Marine Research, its clients or any claims related to the application of information found within its research. This report has been made on the request of the client and is wholly the client's property. This report may not be reproduced and/or published partially or in its entirety without the express written consent of the client. 


\section{Contents}

$\begin{array}{lr}\text { Summary } & 4\end{array}$

1 Introduction $\quad 5$

$2 \quad$ Algorithms description and improvements $\quad 6$

$\begin{array}{lll}2.1 & \text { Statistical classification } & 7\end{array}$

$\begin{array}{lll}2.1 .1 & \text { Method description } & 7\end{array}$

2.1.2 Improvement of the software $\quad 8$

2.2 Frequency response classification $\quad 8$

2.2.1 Method description $\quad 8$

$\begin{array}{ll}\text { 2.2.2 Improvement of the software } & 11\end{array}$

$\begin{array}{lr}\text { References } & 12\end{array}$

$\begin{array}{lr}\text { Quality Assurance } & 13\end{array}$

$\begin{array}{lr}\text { J ustification } & 14\end{array}$ 


\section{Summary}

The EU has by means of new policy restricted the discarding of fish at sea, including bycatch and slipping. As a result, the fishing industry now requires improved methods to identify fish species and size before the catch process begins. With the introduction of robust broadband echosounder (i.e. downward looking sonar) on the market, active acoustic data now have the potential for improved target discrimination for both type and size (i.e. determine fish species and size).

The aim of this project is to develop methods for fish classification and size estimation using data from broadband echosounder and further implement them into a software for near-real time viewing. Such a software would help skippers to take better informed decisions while fishing.

This project is running over three years (June 2016 to June 2019) in collaboration between Wageningen Marine Research (WMR), Redersvereniging voor de Zeevisserij (RVZ) and TNO. This document reports on the improvement of the methods used for fish species classification.

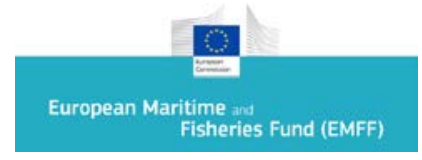

\section{TNO}
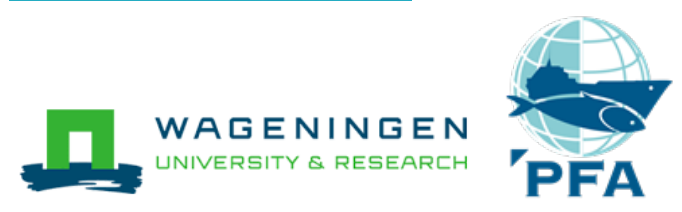


\section{$1 \quad$ Introduction}

The EU has by means of new policy restricted the discarding of fish at sea, including bycatch and slipping. As a result, the fishing industry now requires improved methods to identify fish species and size before the catch process begins. With the introduction of robust broadband echosounder (i.e. downward looking sonar) on the market, active acoustic data now have the potential for improved target discrimination for both type and size (i.e. determine fish species and size).

The aim of this project is to develop methods for fish classification and size estimation using data from broadband echosounder and further implement them into a software for near-real time viewing. Such a software would help skippers to take better informed decisions while fishing.

This project is running over three years (June 2016 to June 2019) in collaboration between Wageningen Marine Research (WMR), Redersvereniging voor de Zeevisserij (RVZ) and TNO.

This document describes the work carried out in Task 3.4 of Work package 3: "Improving species classification algorithm" (Figure 1). Drawing on the previous project "VIP use of new broadband echosounder"1, algorithm development is carried out by WMR and TNO. Here, a short introduction to these algorithms will be given and substantial improvements and new features relative to the previous project will be described.

\begin{tabular}{|c|l|l|l|}
\hline Item \# & Tasks & \multicolumn{2}{|l|}{} \\
\hline & Fish classification algorithm development for BBES & TNO & Imares \\
\hline WP1 & System calibration & & $\mathrm{X}$ \\
\hline T1.1 & Calibration in the field & & $\mathrm{X}$ \\
\hline WP2 & Data collection & $\mathrm{X}$ \\
\hline T2.1 & fishing trips (mackerel, horse mackerel, herring, sprat) & $\mathrm{X}$ \\
\hline T2.2 & research trips (mackerel, herring, sprat) & $\mathrm{X}$ \\
\hline WP3 & Data processing \& analysis & $\mathrm{X}$ \\
\hline T3.1 & fishing trips (mackerel, horse mackerel, herring, sprat) & $\mathrm{X}$ \\
\hline T3.2 & research trip (mackerel, herring, sprat) & $\mathrm{X}$ \\
\hline T3.3 & database setup & $\mathrm{X}$ & $\mathrm{X}$ \\
\hline T3.4 & species identification algorithm improvement & $\mathrm{X}$ \\
\hline T3.5 & fish length estimation method development & $\mathrm{X}$ \\
\hline WP4 & Demonstrator software development & $\mathrm{X}$ \\
\hline T4.1 & $\begin{array}{l}\text { first demonstrator software version (GUI 1): pre-processing, } \\
\text { imaging, noise reduction, school detection, species classification }\end{array}$ & $\mathrm{X}$ \\
\hline T4.2 & second demonstrator software version (GUI 2): implementation of \\
\hline T4.3 & installation, test \& evaluation GUI 1 & $\mathrm{X}$ & $\mathrm{X}$ \\
\hline T4.4 & installation, test \& evaluation GUI 2 & $\mathrm{X}$ \\
\hline WP5 & WP 7 Management, communication \& reporting & $\mathrm{X}$ \\
\hline T5.1 & Project progress monitoring \& reporting & $\mathrm{X}$ & $\mathrm{X}$ \\
\hline T5.2 & Project management and communication & $\mathrm{X}$ & $\mathrm{X}$ \\
\hline T5.3 & Report and presentation of results & $\mathrm{X}$ \\
\hline & & $\mathrm{X}$ & $\mathrm{X}$ \\
\hline & $\mathrm{X}$ & $\mathrm{X}$ \\
\hline
\end{tabular}

Table 1: Overview of work packages and tasks for the realFishEcho project. 


\section{Algorithms description and improvements}

In term of pre-processing of the acoustic data, it consists of an echogram enhancement followed by a fish school detection, similarly to the previous project ${ }^{1}$. Diagrams exemplifying these processing steps are shown in Figure 1(a) and (b). Further details about each processing step are given in Fassler et al. ${ }^{1}$.
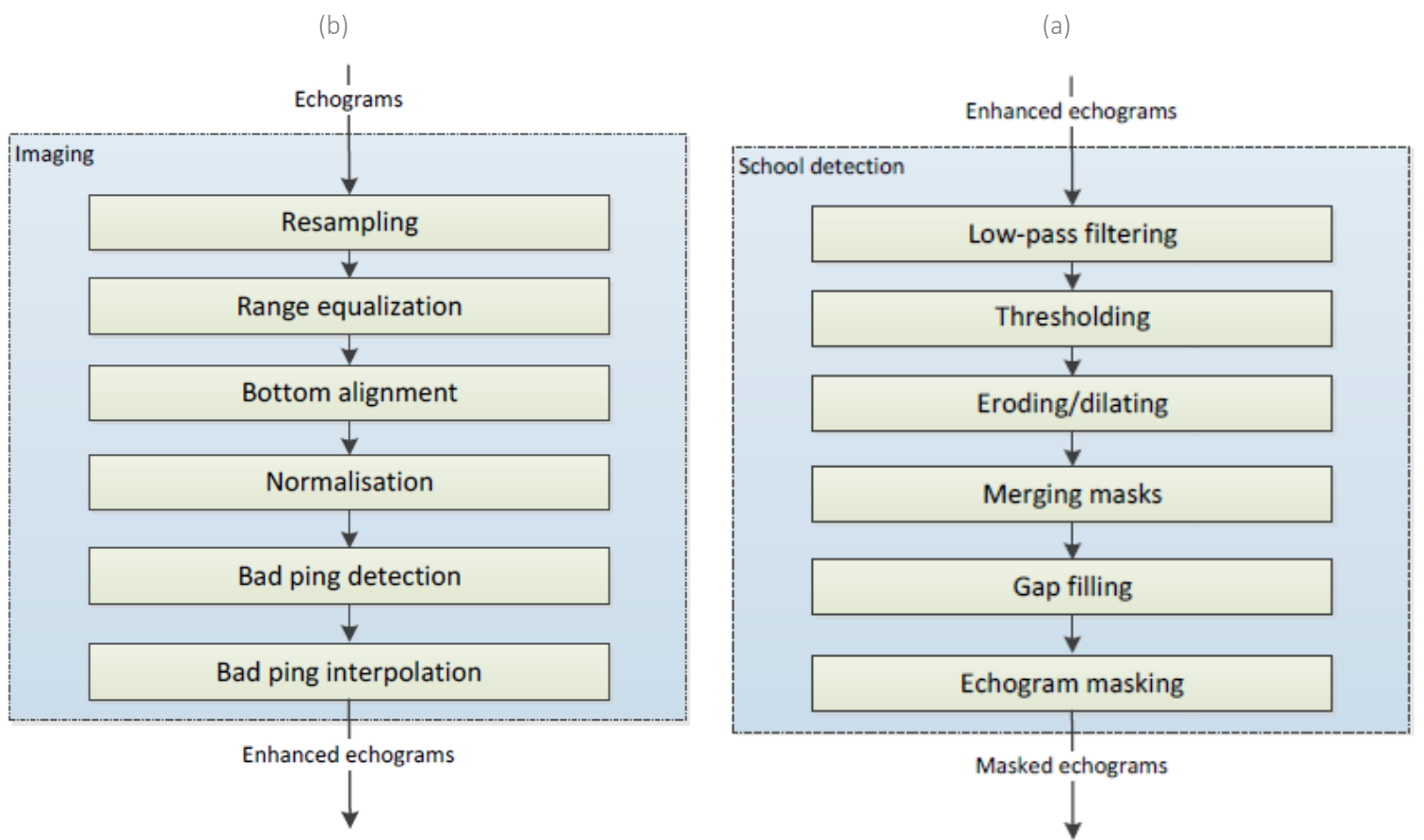

Figure 1: Pre-processing workflow. (a): echogram enhancement processing steps. (b): school detection processing steps. Extracted from Fassler et al. ${ }^{1}$.

For species classification, three approaches are employed:

- $\quad$ statistical classification aimed at identifying species based on statistical features contained in the acoustic data and resulting images; e.g. related to school size, shape, echo intensity distribution, school density, time signals etc

- frequency response classification based on the enhanced frequency spectrum available from the broadband data, which should theoretically differ between different types and shapes of fish species

- combined classification (not implemented yet)

The statistical classification follows a similar approach to the one from the previous project while the frequency response classification has undergone more developments. The frequency response classification was based on a trend analysis and is now using a machine learning (Neural Network) approach.

Also, there is general improvements benefiting the species classification algorithm: (1) access to more data (2) improved data organisation (3) development of a specific data format for algorithm training. The development of improved data organisation and specific data format allows one to reduce each data sets to fish schools (Figure 2) and therefore to update the algorithm with new data more easily. In term of data, only 3 data sets were available from only one vessel in the last project ${ }^{1}$. Here, this has been expanded to 8 data sets (with the same species, Horse Mackerel, Herring, Mackerel) from four different vessels ( 3 commercial vessels, 1 research vessel, see Berges et al. $^{2}$ for more details). 


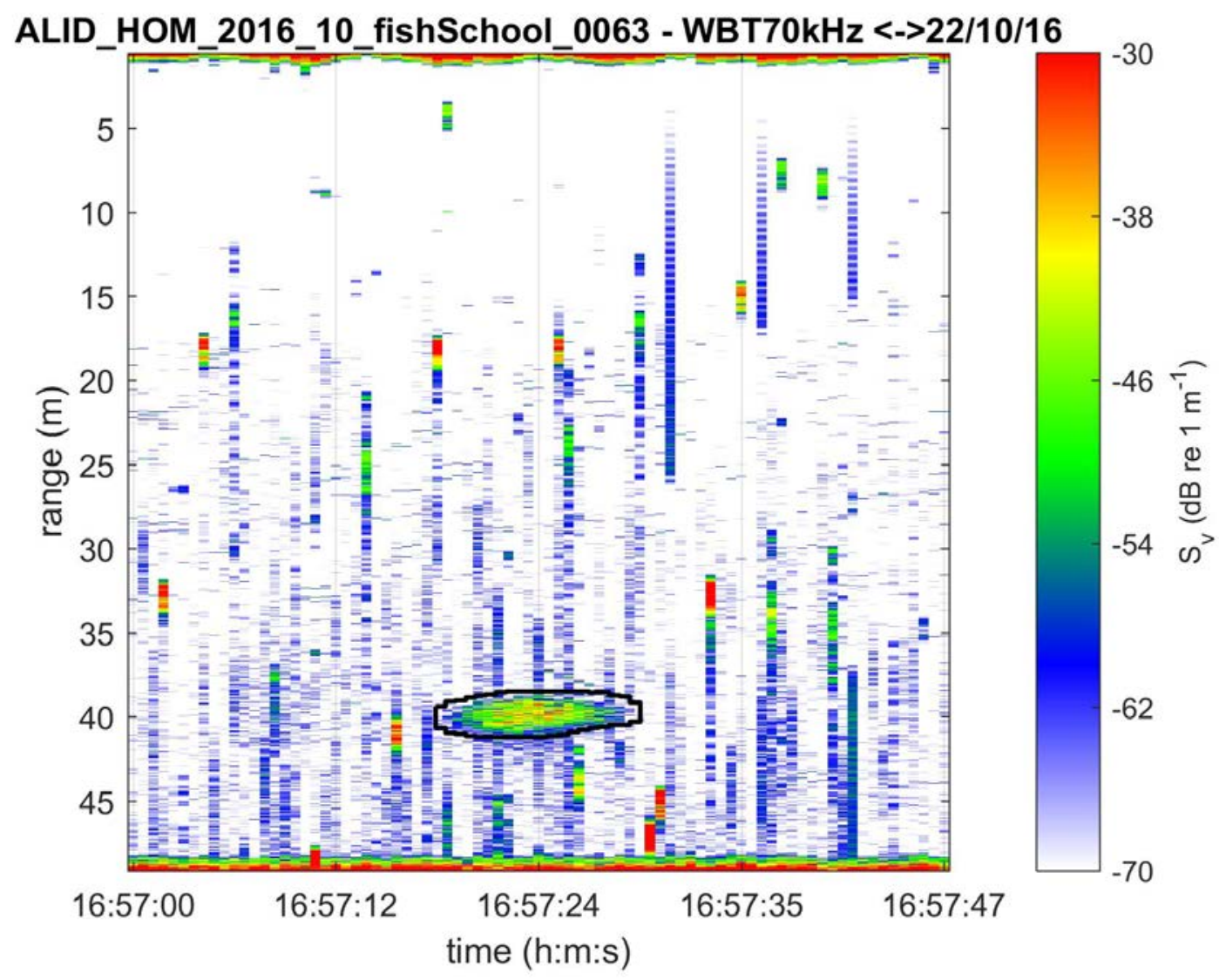

Figure 2: Echogram example of reduced data. The data of the fish school is selected with 30 pings before and after the school and converted into a specific data format.

\section{$2.1 \quad$ Statistical classification}

\subsubsection{Method description}

A number of simple as well as more complex features are derived from the pre-processed data (Figure 1). These features are related to statistical properties of a given fish school and are different among different fish species. The differences between fish species are the basis for species identification. In addition, in order to make the classification more robust against environmental and electronic interferences, some of the features are also computed for the background data, i.e. data at various locations in the water column.

For the statistical classification, the training data set is made of statistical features that are computed for numerous fish schools of the different fish species of interest. This training data set is used for: (1) testing the ability of each feature to discriminate each species; (2) assess classification efficiency of each feature. Base on this dataset, the classifier uses features of all species to derive equations that takes the form of decision boundaries between classes (e.g. Figure 3). The decision boundary is the end results of the algorithm training process. Further, using the trained classifier on unknown test samples, the same feature or combination of features are computed and provided as an input to the classifier. Using the "trained" decision boundaries, the classifier is then able to determine on which side of the decision boundary the sample lays, providing the classification decision. The type of classifier determines how the boundaries are derived. Several common classifiers derive their boundary using the following approaches:

- K-nearest neighbours: for each test sample it determines the distance to the $\mathrm{K}$ closest training samples of each class. The class with the shortest distance is the classification output. 
- NMC: Nearest Mean Classifier. For each test sample it computes the distance to the average of all training samples of a class. This is done for every class; the class with the shortest distance is the classification output.

- $\quad$ SVC: Support Vector Classifier. A support vector classifier is a discriminative classifier defined by a separating hyperplane or maximum margin separator: a linear decision boundary with the largest possible distance from the decision boundary to the training samples it separates.

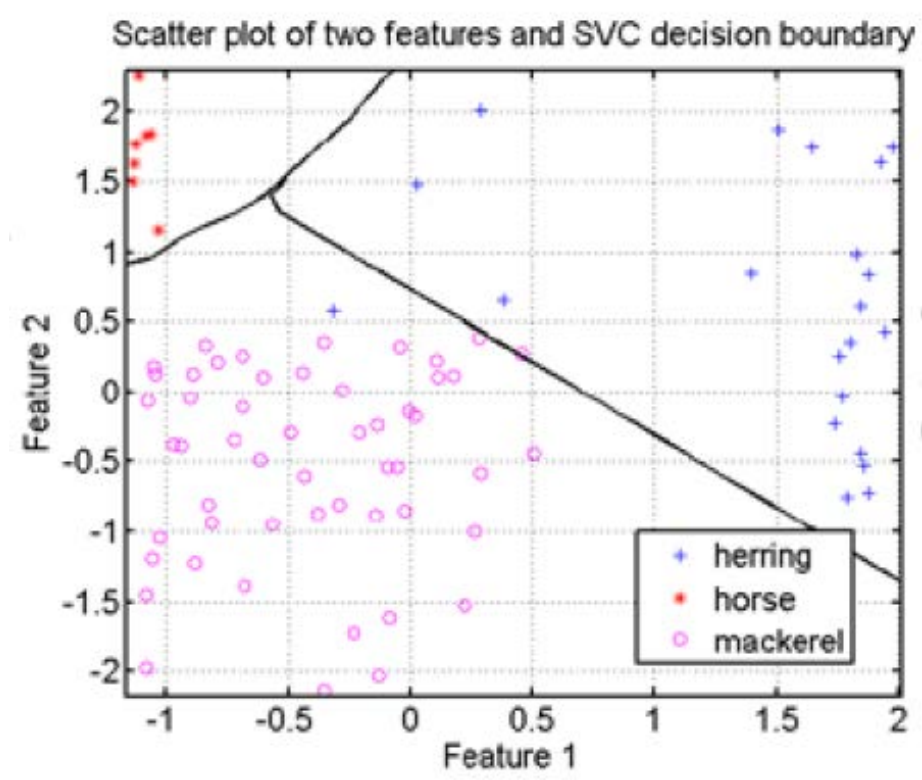

Figure 3: Statistical classification. Showing 2 features plotted against each other and the clear separation between the different species.

\subsubsection{Improvement of the software}

The improvements for the statistical classification are twofold:

- It has been changed from a school classifier to a school part classifier.

- The amount of data available for training is larger, thus providing more robust classification.

\subsection{Frequency response classification}

\subsubsection{Method description}

The frequency response classification is using machine learning approach, more specifically a Neural Network method ${ }^{3,4}$ (NN). This consists of interconnected processing elements that after appropriate training are able to solve a specific problem. Here, the problem consists on determining the fish species given frequency response measurements.

A NN is typically constituted of several layers of neurons: input layers, hidden layers where undergoes the classification process (through application of weights, biases and operators) and output layers, yielding the final scores for the classification.

Here, the input to the $N N$ is the thresholded and normalized spectrum (see Figure 4) measured by the wideband echosounder for the following WBT channels: $70 \mathrm{kHz}$ WBT, $120 \mathrm{kHz}$ WBT, $200 \mathrm{kHz}$ WBT. The normalization process consists of bounding the maximum and minimum of each spectrum between -1 and 1 based on two threshold boundaries. The frequency response is expected to vary significantly between fish species and to a lessened extent with depth and area ${ }^{1,5,6}$. More specifically, the number of inputs to the NN is the number of frequency bins the spectrum is divided into. This is further fed into the various layers of the NN. Here, an architecture optimized for pattern recognition is used (Figure 4). It consists of 1 hidden layer and 1 output layer. 
The output is of size $3 \times 1,1$ output for each fish species (Horse Mackerel HOM, Herring HER, Mackerel MAC) while the number of neuron for the hidden layer is set to 50 . The way the NN adapts to a particular problem is by adjusting weights ( $w_{1}$ and $w_{2}$ in Figure 4$)$ and biases $\left(b_{1}\right.$ and $b_{2}$ in Figure 4) for each neuron in each layer.

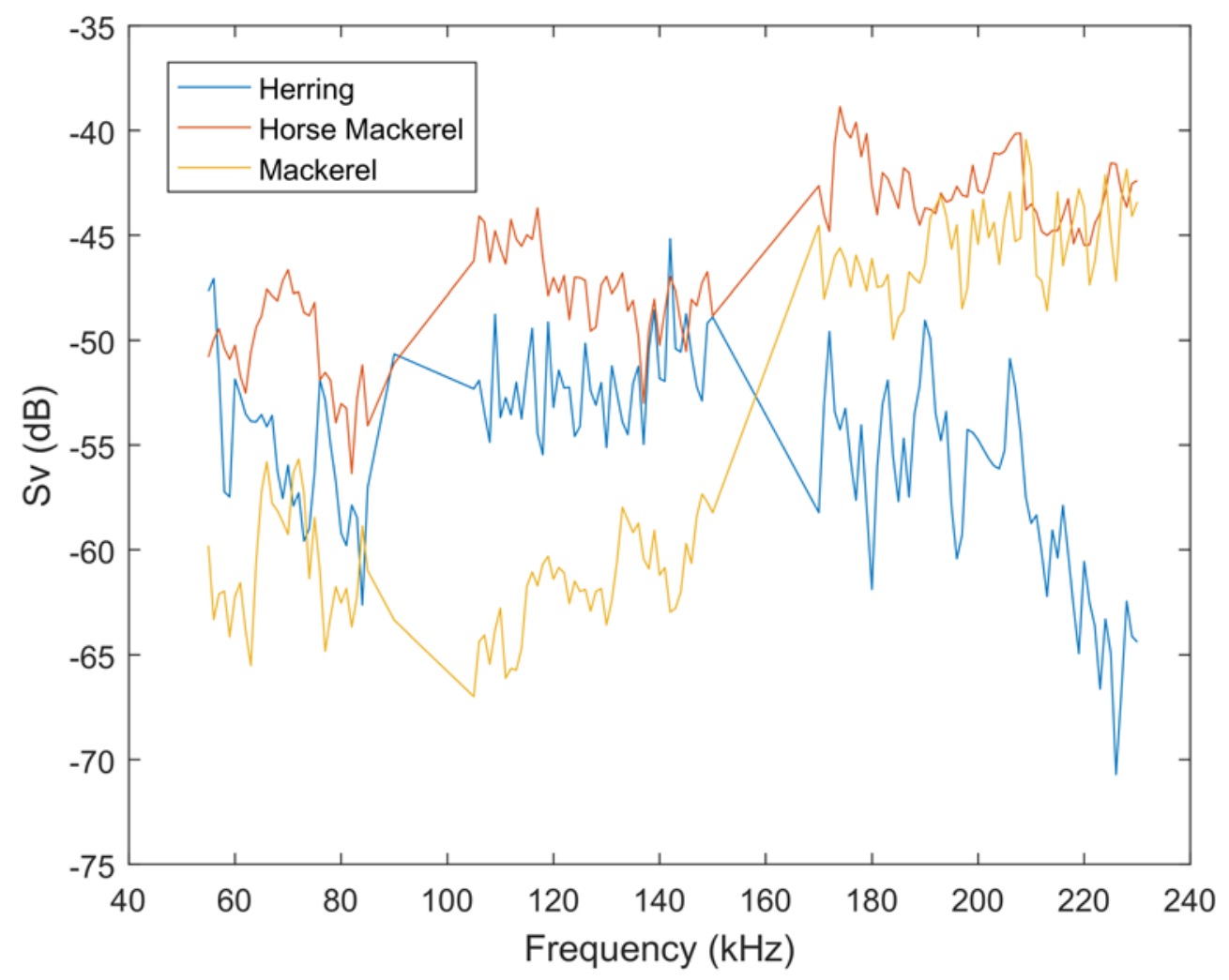

Figure 4: Spectrum levels (as backscattering volume strengths, i.e. $\mathrm{Sv}^{7}$ ) example for: Herring (blue line), Horse Mackerel (red line) and Mackerel (yellow line). Before being inputted to the NN, these spectrum are normalized between -1 and 1 using a threshold as boundaries (e.g. $-120 \mathrm{~dB}$ to $-30 \mathrm{~dB}$ ).

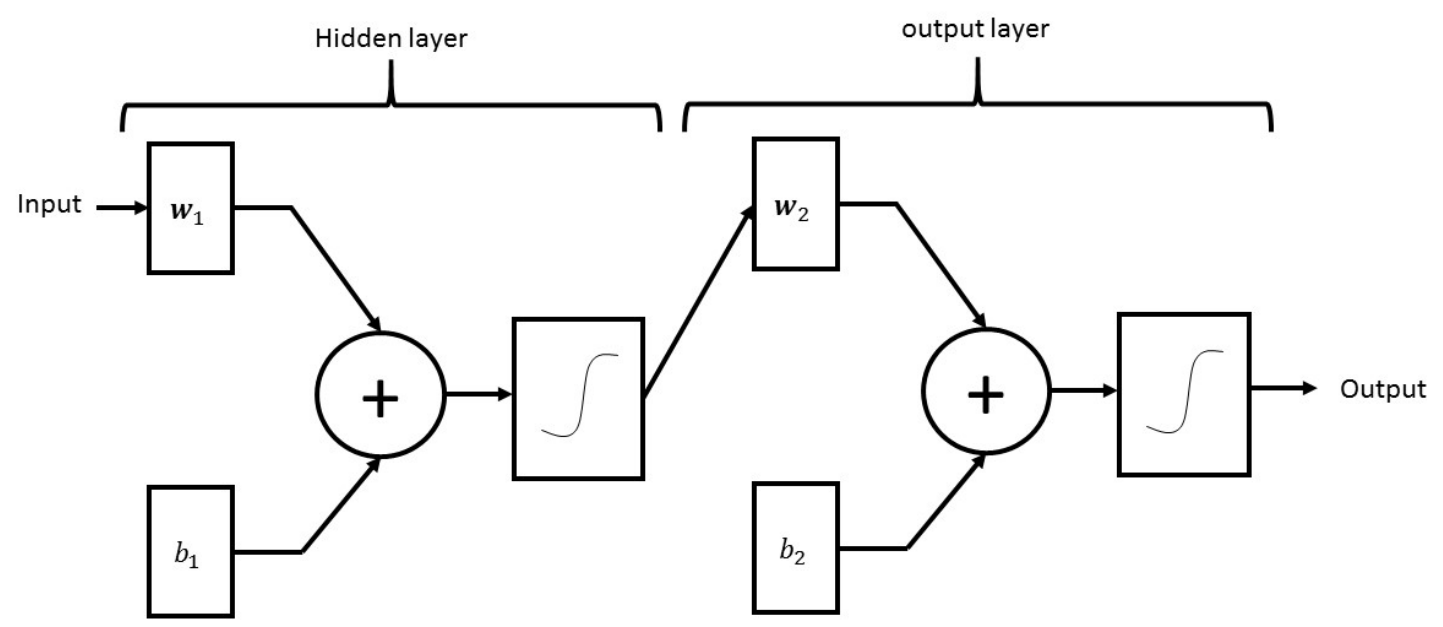

Figure 5: Schematic of NN architecture used here. This is composed of 2 layer, hidden and output layers. 
The adjustment of the weights and biases is performed prior to the use of the NN in a real situation, during a process a training, validating and testing the NN. This is done using a data set that consists of echosounder records of various fish schools of all three species. It is also associated with robust ground truth in the form of catch samples. This data set is divided into three components:

- Training: these data are used to compute weights and biases through various iterations.

- Validation: these data are used to validate the $\mathrm{NN}$ and make sure it does not become too specialised with respect to the training data.

- Testing: these data are used to assess the performance of the NN after the training it completed.

A NN training performed for fish school classification is shown in Figure 5. A training data set is made of several inputs samples (frequency response) together with associated outputs (fish species). The weight and biases are adjusted for each sample using a backpropagation algorithm ${ }^{3}$. This is repeated several times over the training data set and each iteration is called an "epoch" ( $x$-axis in Figure 5). At the end of each epoch, an error index is calculated ( $y$-axis in Figure 5, cross-entropy ${ }^{3}$ in this instance) for the training data set and the validation data set. After 10 epochs, one can observe that the error index for the training data set drops rapidly while remaining constant for the validation data set. The set of weights and biases are becoming increasingly optimised for the training data set but not the validation data set. This is because the weights and biases are only updated using the training data set. Though, the validation data is here to ensure that the NN does not loose generality (i.e. is not too specialised to the training data set). Therefore, the optimal training is where the performance of the validation data set is maximized (i.e. minimized error).

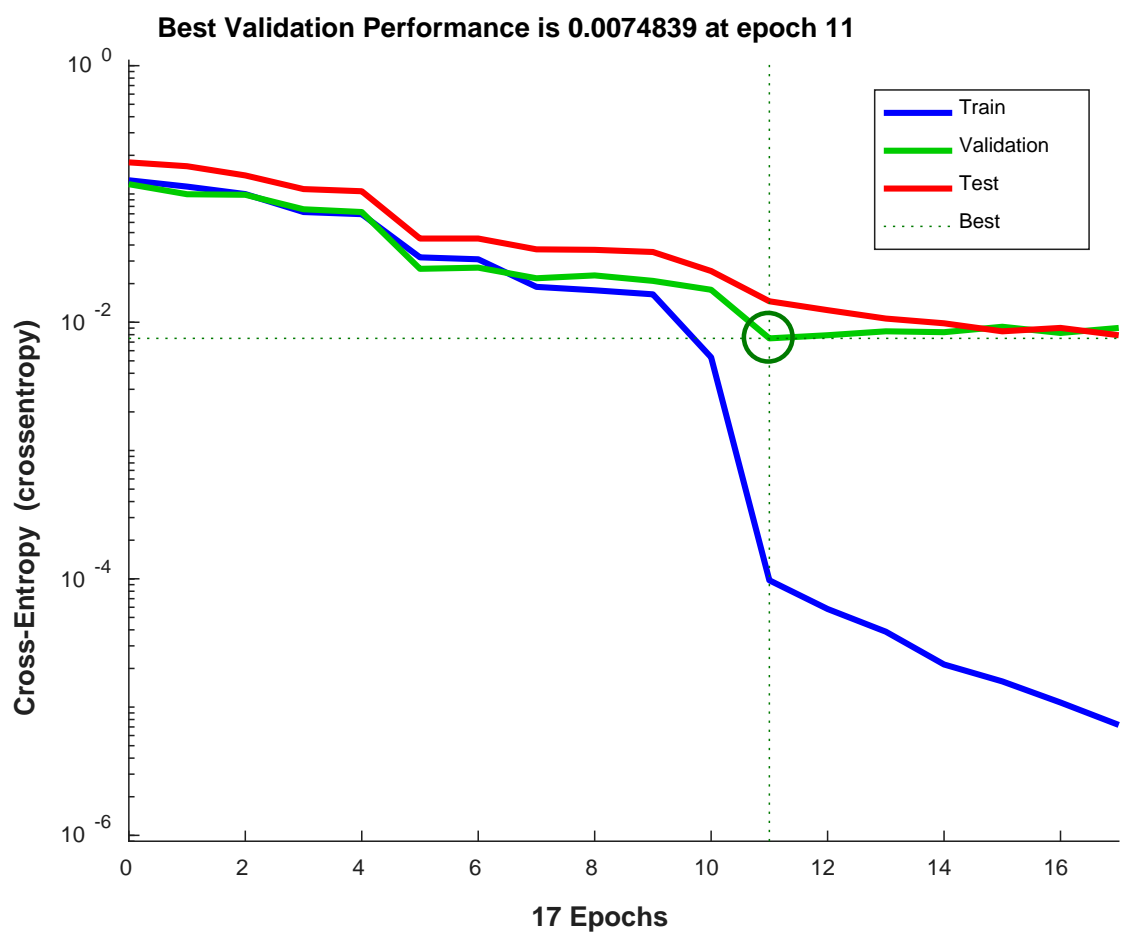

Figure 6: Results from Neural Network training. In this case, the training and validation data sets consist of equal number of spectra of different fish species. The training data set is made of 1000 spectra and the validation data set is made of 500 spectra. The test data set consists of 750 spectra.

In this document, a trial for the NN method described here is used to exemplified typical results. Data used in this trial are Mackerel and Horse Mackerel acoustic data from the Alida vessel (collected on 12/2014 and 10/2016 respectively) and Herring acoustic data from the Tridens II vessel for Herring (collected on 07/2016). Each data set consists of broadband acoustic data recorded around trawls. First, the acoustic data are pre-processed and a fish school detection algorithm is applied. Using catch composition for each trawl, different species (i.e. HER, HOM, MAC) are allocated to relevant detected fish schools (i.e. fish schools with matching time and depth). This constitutes the ground-thruthed data. From these, 750 spectra are selected at random for each species. This makes a data set of 2250 spectra in total. With equal number of samples for each species, the test data set is made of 750 samples and the training and validation data set is made of 1500 samples. 
Using the training shown in Figure 6 (using backpropagation), the test data is processed using the trained NN. The results are shown in Figure 7, displayed in a confusion matrix. Such a plot allows one to observe the performances of the NN for different classes. For each classes, the amount of correct and incorrect classifications are displayed. In this example, it can be observed that over 750 samples, 14 cases are miss-classified: 10 cases were classified as HOM while being HER and 4 instances where classified as HOM while being HER. These results shown here are only trial results and the performance of the $\mathrm{NN}$ will be improved as further analysis are being carried out and more data are available through the project.

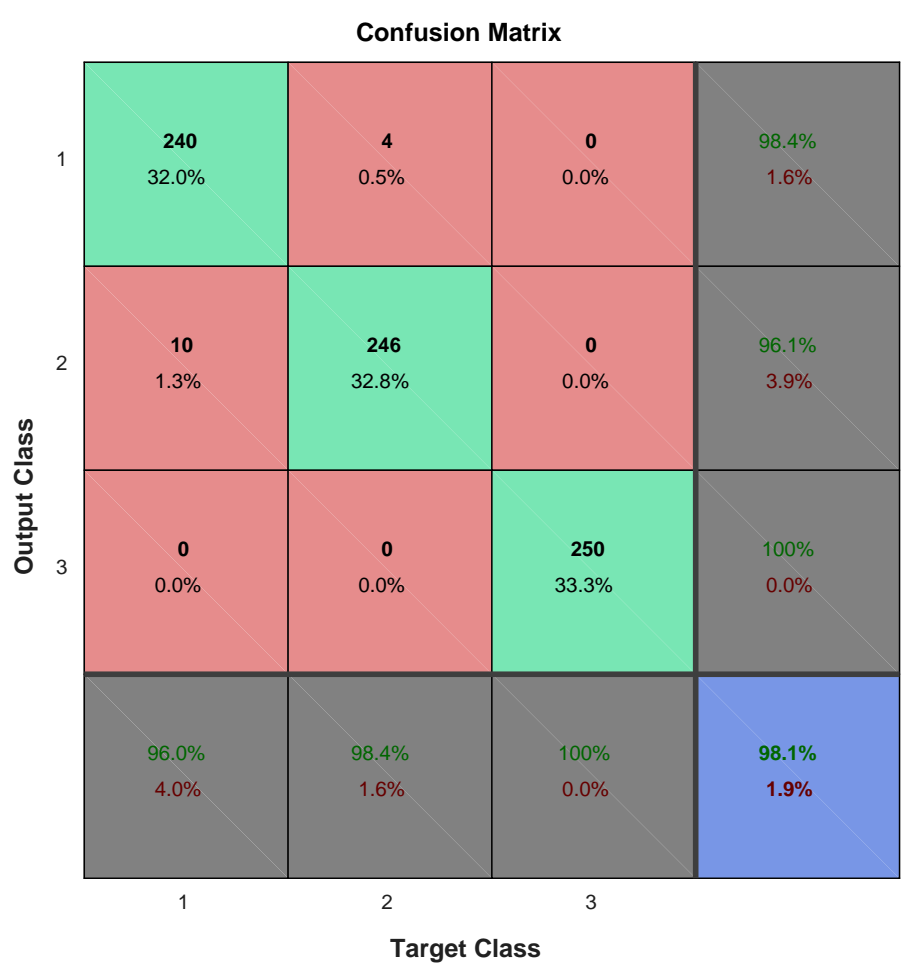

Figure 7: Confusion matrix based on 1500 samples (Sv spectra) from three different datasets. Classes are the following: 1 is Herring (HER), 2 is Horse Mackerel (HOM), 3 is Mackerel (MAC). The results show that there was 14 cases that were miss-classified: 10 cases were classified as HOM while being HER and 4 instances where classified as HOM while being HER.

\subsubsection{Improvement of the software}

In the previous project ${ }^{1}$, the frequency response classification was performed using a dynamic factor analysis ${ }^{8}$. This allowed to determined different frequency response trends between fish species. In the realFishEcho project, this is now changed to a NN because of: (1) its known ability for pattern recognition $^{3,9}(2)$ the easiness to improve training as the number of data sets available grows and one refine the data analysis (3) the potential ability to provide a school part (e.g. pixel level) classifier. In addition, there is the potential for further improvement of the NN by using an extended sets of parameters (e.g. distance to seafloor, size of school...), various training methods or different NN architectures. 


\section{References}

1. Fassler, S. M. M. et al. VIP report 'Use of new broadband echosounder': Techniques for improved ocean imaging and selectivity in pelagic fisheries. IMARES Rep. C171/ 15, 100 (2015).

2. Berges, B. J. P., Sakina, S. \& van Helmond, E. Practical implementation of real-time fish classification from acoustic broadband echo sounder data - RealFishEcho progress report: Year 1 - June 2017. (WMR report no 17.006, 2017).

3. Hagan, M. T., Demuth, H. B., Beale, M. H. \& De Jesús, O. Neural network design. ([publisher not identified], 2014).

4. Simmonds, J., Armstrong, F. \& Copland, P. J. Species identification using wideband backscatter with neural network and discriminant analysis. ICES J. Mar. Sci. 53, 189-195 (1996).

5. Fässler, S. M. M., Santos, R., García-Núñez, N. \& Fernandes, P. G. Multifrequency backscattering properties of Atlantic herring ( Clupea harengus) and Norway pout ( Trisopterus esmarkii ). Can. J. Fish. Aquat. Sci. 64, 362-374 (2007).

6. Simmonds, E. J. \& MacLennan, D. N. Fisheries acoustics: theory and practice. Fish and aquatic resources series; (Blackwell Science, 2005).

7. Maclennan, D., Fernandes, P. G. \& Dalen, J. A consistent approach to definitions and symbols in fisheries acoustics. ICES J. Mar. Sci. 59, 365- 369 (2002).

8. Zuur, A. F., Fryer, R. J., Jolliffe, I. T., Dekker, R. \& Beukema, J. J. Estimating common trends in multivariate time series using dynamic factor analysis. Environmetrics 14, 665-685 (2003).

9. Antona, A. Remote Fish Species and Size Identification Using Broadband Echosounders. (Wageningen UR, 2016). 


\section{Quality Assurance}

Wageningen Marine Research utilises an ISO 9001:2008 certified quality management system (certificate number: 187378-2015-AQ-NLD-RvA). This certificate is valid until 15 September 2018. The organisation has been certified since 27 February 2001. The certification was issued by DNV Certification B.V.

Furthermore, the chemical laboratory at IJ muiden has NEN-EN-ISO/IEC 17025:2005 accreditation for test laboratories with number L097. This accreditation is valid until $1^{\text {th }}$ of April 2021 and was first issued on 27 March 1997. Accreditation was granted by the Council for Accreditation. The chemical laboratory at IJ muiden has thus demonstrated its ability to provide valid results according a technically competent manner and to work according to the ISO 17025 standard. The scope (L097) of de accredited analytical methods can be found at the website of the Council for Accreditation (www.rva.nl).

On the basis of this accreditation, the quality characteristic $\mathrm{Q}$ is awarded to the results of those components which are incorporated in the scope, provided they comply with all quality requirements. The quality characteristic $\mathrm{Q}$ is stated in the tables with the results. If, the quality characteristic $\mathrm{Q}$ is not mentioned, the reason why is explained.

The quality of the test methods is ensured in various ways. The accuracy of the analysis is regularly assessed by participation in inter-laboratory performance studies including those organized by QUASIMEME. If no inter-laboratory study is available, a second-level control is performed. In addition, a first-level control is performed for each series of measurements.

In addition to the line controls the following general quality controls are carried out:

- Blank research.

- Recovery.

- Internal standard

- Injection standard.

- Sensitivity.

The above controls are described in Wageningen Marine Research working instruction ISW 2.10.2.105. If desired, information regarding the performance characteristics of the analytical methods is available at the chemical laboratory at IJ muiden.

If the quality cannot be guaranteed, appropriate measures are taken. 


\section{Justification}

Report C010/18

Project Number: 4311400004

The scientific quality of this report has been peer reviewed by a colleague scientist and a member of the Management Team of Wageningen Marine Research

Approved:

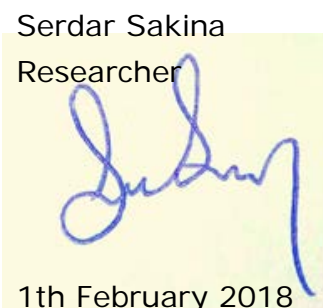

Approved:

Drs. J. Asjes

Manager Integration

Signature:

Date:

$8^{\text {th }}$ February 2018 
Wageningen Marine Research

T +31 (0)317480900

E: marine-research@wur.nl

www.wur.eu/marine-research

Visitors' address

- Ankerpark 27, 1781 AG Den Helder

- Korringaweg 5, 4401 NT Yerseke

- Haringkade 1, 1976 CP IJ muiden
Wageningen Marine Research is the Netherlands research institute established to provide the scientific support that is essential for developing policies and innovation in respect of the marine environment, fishery activities, aquaculture and the maritime sector.

\section{Wageningen University \& Research:}

is specialised in the domain of healthy food and living environment.

\section{The Wageningen Marine Research vision}

'To explore the potential of marine nature to improve the quality of life'

\section{The Wageningen Marine Research mission}

- To conduct research with the aim of acquiring knowledge and offering advice on the sustainable management and use of marine and coastal areas.

- Wageningen Marine Research is an independent, leading scientific research institute

Wageningen Marine Research is part of the international knowledge organisation Wageningen UR (University \& Research centre). Within Wageningen UR, nine specialised research institutes of the Stichting Wageningen Research Foundation have joined forces with Wageningen University to help answer the most important questions in the domain of healthy food and living environment. 